\title{
Is there a relationship between weather conditions and aortic dissection?
}

\author{
Costa Repanos*1,3 and Neil K Chadha ${ }^{2,3}$
}

\author{
Address: ${ }^{1}$ ENT Department, Derriford Hospital, Plymouth, United Kingdom, ${ }^{2}$ ENT Department, Torbay Hospital, Torquay, United Kingdom and \\ 3Blackpool Victoria Hospital, Blackpool, United Kingdom \\ Email: Costa Repanos* - costa@repanos.com; Neil K Chadha - neil.chadha@entsouthwest.co.uk \\ * Corresponding author
}

Published: 15 October 2005

BMC Surgery 2005, 5:21 doi:10.1 I86/147|-2482-5-21

This article is available from: http://www.biomedcentral.com/|47|-2482/5/2I

(C) 2005 Repanos and Chadha; licensee BioMed Central Ltd.

This is an Open Access article distributed under the terms of the Creative Commons Attribution License (http://creativecommons.org/licenses/by/2.0), which permits unrestricted use, distribution, and reproduction in any medium, provided the original work is properly cited.
Received: 03 December 2004

Accepted: 15 October 2005

\begin{abstract}
Background: Bleeding and rupture of blood vessels has been correlated with weather conditions in the past. This is the first study in the world literature with the aim of investigating the relationship between atmospheric pressure and temperature with the presentation of aortic dissection.

Methods: The dates of all emergency aortic dissection repairs from 1996-2002 in a regional cardiothoracic unit at Blackpool Victoria Hospital were obtained. Hourly temperature and pressure data from a regional weather station for this time period was supplied by the Meteorological Office. The mean and standard deviation of hourly temperature and pressure data for that month were compared to the mean and standard deviation of the data 24 and 48 hours prior to the aortic dissection.
\end{abstract}

Results: 26 patients were found to have been operated on during the time period studied. There was no statistically significant correlation between temperature or atmospheric pressure readings, and the incidence of aortic dissection, using a Bonferonni-corrected significance p-value of 0.005

Conclusion: This study is the first to examine the relationship between atmospheric pressure, temperature and dissecting thoracic aorta. No statistically significant relationship was demonstrable.

\section{Background}

Aortic dissection occurs when there is a defect in the intimal layer of the aorta. This causes blood to track through the aortic layers, creating a false lumen between the intima and the overlying adventitia, tending to obliterate the blood supply to branches along its route. The dissection may spread distally to involve the renal, spinal and iliac arteries, or proximally to involve the head and neck vessels, coronary vessels, or aortic root. Once the dissection has occurred it can rupture into the main lumen itself, in which case the patient may survive for some time, or rupture externally leading to haemorrhage and potentially a rapid death.

The known risk factors for aortic dissection are male sex, hypertension, atherosclerosis, diabetes, hyperlipidemia, smoking, syphilis, Marfan's disease, and Ehlers-Danlos disease. In a large series of necropsies of acute aortic dissections more than $40 \%$ of patients with proximal dissection died immediately, the rate of death ranged between 1 and 3\% per hour. Within 24 hours 70\%, within 1 week $94 \%$ and within 5 weeks $100 \%$ of people with proximal 
aortic dissection died [1]. After surgical treatment of proximal aortic dissection the survival rate is approximately $70 \%$ after 3 years [2].

The aetiology of an acute aortic dissection remains poorly understood. It is thought that the moment of dissection may be precipitated by higher than normal blood pressures, and it has been postulated that variablilty of atmospheric pressure may add to this. There is also a seasonal variation in blood pressure $[3,4]$ and it has been shown that there is a seasonal increase in the rate of non-traumatic aortic dissections in the winter $[5,6]$.

Previous work has observed an increase in ruptured abdominal aortic aneurysms (AAA) in winter [7], and a correlation with atmospheric pressure [8]. Other vascular disruptions, including subarachnoid aneurysm rupture and spontaneous cervical artery dissection, have also been demonstrated to correlate with atmospheric pressure changes [9] or seasonal variations [10].

There have been no previous studies specifically investigating the relationship between weather conditions and the incidence of thoracic aortic dissection. Considering the similarity in seasonal incidence between AAA rupture and aortic dissection, we aim to explore whether there is an association between atmospheric pressure, temperature, and the presentation of aortic dissection.

\section{Methods}

Hospital records were used to identify all emergency aortic dissection repairs between 1996 and 2002 in a regional cardiothoracic unit at Blackpool Victoria Hospital. Data was available from the cardiothoracic minimum dataset, and cases were confirmed by reference to the hospital notes. Ethical approval was obtained to use this data. Temperature and pressure recordings from a nearby regional weather station were obtained for this time period from the United Kingdom Meteorological Office. Blackpool cardiothoracic unit receives referrals from northern Lancashire, and Crosby is the weather station closest to the centre of the unit's catchment area.

The meteorological data used was hourly temperature measurements and hourly atmospheric pressure measurement for a full month centred on the occurrence of each aortic dissection.

Using the meteorological data, the following temperature indicators were calculated (Table 1):

The following pressure indicators were also calculated (Table 2):
Table I: Temperature indicators

\begin{tabular}{ll}
\hline I & Mean temperature for the whole month of the operation \\
2 & Mean temperature 48 hours before operation date \\
3 & Mean temperature 24 hours before operation date \\
4 & Mean daily temperature range for the whole month of the \\
& operation \\
6 & Mean daily temperature range 48 hours before operation date \\
6 & Mean daily temperature range 24 hours before operation date
\end{tabular}

\section{Table 2: Pressure indicators}

\begin{tabular}{ll}
\hline 7 & Mean pressure for the whole month of the operation \\
8 & Mean pressure 48 hours before operation date \\
9 & Mean pressure 24 hours before operation date \\
I0 & Mean daily pressure range for the whole month of the \\
I I & Mean daily pressure range 48 hours before operation date \\
I2 & Mean daily pressure range 24 hours before operation date \\
I3 & Standard deviation of pressure for the whole month \\
I4 & Standard deviation of pressure 48 hours before operation date \\
I5 & Standard deviation of pressure 24 hours before operation date
\end{tabular}

Indicators were then paired for comparison using each set of monthly data against the corresponding data from 48 hours, and then 24 hours before the operation. The null hypothesis was that there were no differences within each pair of indicators. These hypotheses were tested using paired t-tests and Wilcoxen signed rank tests (depending on the distribution of the data).

The Bonferroni correction is a statistical adjustment to allow for multiple comparisons. A Bonferroni correction was applied by dividing the p-values by the number of outcomes being tested. In this study we have made 10 comparisons between indicators, and have therefore used $\alpha=0.005$ for hypothesis testing. The null hypothesis was therefore rejected for $p$ values $\leq 0.005$, and the probability of making a Type I error therefore 0.05.

\section{Results}

Data for 26 consecutive operated dissecting aortic aneurysms were obtained for the study time period. Results for the temperature indicators and atmospheric pressure indicators including comparisons between pairs are shown in Table 3 and Table 4 respectively.

Table 3 and 4 compare both mean temperature and pressure over the month of the event to the mean temperature and pressures respectively over the preceding 24 and 48 hours. 
Table 4: Pressure indicator values and comparison of results.

\begin{tabular}{|c|c|c|c|c|c|c|}
\hline \multirow[t]{2}{*}{ Indicator A } & \multirow{2}{*}{$\begin{array}{c}\text { Mean of A } \\
\text { (millibars) } n=26\end{array}$} & \multirow[t]{2}{*}{ Indicator B } & \multirow{2}{*}{$\begin{array}{c}\text { Mean of B } \\
\text { (millibars) } n=26\end{array}$} & \multicolumn{2}{|c|}{ Indicator A vs. Indicator B } & \multirow[t]{2}{*}{ P-value } \\
\hline & & & & $\begin{array}{l}\text { Paired t-test ( } \mathrm{t} \text { - } \\
\text { value) }\end{array}$ & $\begin{array}{l}\text { Wilcoxon signed } \\
\text { rank test (z-value) }\end{array}$ & \\
\hline $\begin{array}{l}\text { Mean pressure for } \\
\text { whole month }\end{array}$ & 1011.32 & $\begin{array}{l}\text { Mean pressure } 48 \\
\text { hours before }\end{array}$ & 1009.39 & N/A & 0.724 & 0.469 \\
\hline $\begin{array}{l}\text { Mean pressure for } \\
\text { whole month }\end{array}$ & 1011.32 & $\begin{array}{l}\text { Mean pressure } 24 \\
\text { hours before }\end{array}$ & 1009.88 & N/A & 0.444 & 0.657 \\
\hline $\begin{array}{l}\text { Pressure range for } \\
\text { the whole month }\end{array}$ & 6.99 & $\begin{array}{l}\text { Pressure range } 48 \\
\text { hours before }\end{array}$ & 8.51 & $N / A$ & -1.943 & 0.052 \\
\hline $\begin{array}{l}\text { Pressure range for } \\
\text { whole month }\end{array}$ & 6.99 & $\begin{array}{l}\text { Pressure range } 24 \\
\text { hours before }\end{array}$ & 8.40 & -1.9275 & N/A & 0.065 \\
\hline $\begin{array}{l}\text { Standard deviation } \\
\text { of pressure for } \\
\text { whole month }\end{array}$ & 2.22 & $\begin{array}{l}\text { Standard deviation } \\
\text { of pressure } 48 \\
\text { hours before }\end{array}$ & 2.73 & N/A & -2.283 & 0.022 \\
\hline $\begin{array}{l}\text { Standard deviation } \\
\text { of pressure for } \\
\text { whole month }\end{array}$ & 2.22 & $\begin{array}{l}\text { Standard deviation } \\
\text { of pressure } 24 \\
\text { hours before }\end{array}$ & 2.64 & $N / A$ & -1.905 & 0.057 \\
\hline
\end{tabular}

Table 3: Temperature indicator values and comparison of results.

\begin{tabular}{|c|c|c|c|c|c|}
\hline Indicator A & Mean of $A\left({ }^{\circ} \mathrm{C}\right) n=26$ & Indicator B & Mean of $B\left({ }^{\circ} \mathrm{C}\right) n=26$ & $\begin{array}{l}\text { Indicator A vs. } \\
\text { Indicator B }\end{array}$ & $\mathrm{p}$-value \\
\hline & & & & Paired t-test (t-value) & \\
\hline $\begin{array}{l}\text { Mean temperature for } \\
\text { whole month }\end{array}$ & 11.36 & $\begin{array}{l}\text { Mean temperature } 48 \\
\text { hours before }\end{array}$ & 10.60 & -1.7243 & 0.097 \\
\hline $\begin{array}{l}\text { Mean temperature for } \\
\text { whole month }\end{array}$ & 11.50 & $\begin{array}{l}\text { Mean temperature } 24 \\
\text { hours before }\end{array}$ & 10.91 & 1.4658 & 0.156 \\
\hline $\begin{array}{l}\text { Temperature range } \\
\text { for whole month }\end{array}$ & 5.94 & $\begin{array}{l}\text { Temperature range } 48 \\
\text { hours before }\end{array}$ & 5.54 & 0.9972 & 0.329 \\
\hline $\begin{array}{l}\text { Temperature range } \\
\text { for whole month }\end{array}$ & 5.82 & $\begin{array}{l}\text { Temperature range } 24 \\
\text { hours before }\end{array}$ & 5.62 & 0.4275 & 0.673 \\
\hline
\end{tabular}

The distribution of dissections through the year is represented in Figure 1.

Figure 1 depicts the spread of dissections by the month in which they occurred. The numbers are too small to make any comment about seasonality.

\section{Discussion}

Aortic dissection is a condition that presents infrequently to hospitals and is sometimes initially misdiagnosed. Increasingly as hospitals and sub-speciality departments merge to form larger institutions, they will cover a greater population, and the incidence in hospitals will apparently rise.
In our study the most significant result $(p=0.022)$ showed a trend towards the standard deviation of pressure in the 48 hour period prior to the dissection, being greater than the standard deviation of pressure for that whole month (2.73 vs. 2.22 millibars). This did not reach statistical significance however, after the Bonferroni correction has been applied.

The pressure range was calculated by subtracting the lowest from the highest reading of the day. The mean pressure range for the whole month (6.99 millibars) had a trend towards being lower than the mean 48 hours before dissection ( 8.51 millibars, $\mathrm{p}=0.047$ ) and 24 hours before dissection ( 8.40 millibars, $\mathrm{p}=0.066)$. This was not statistically significant. 


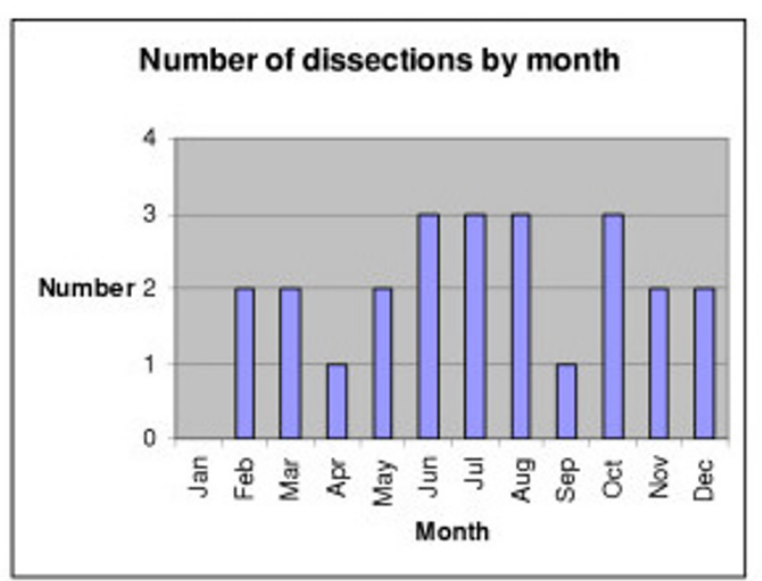

\section{Figure I}

Seasonal variation of aortic dissections (1996-2002).

The incidence of aortic dissection had no seasonal or monthly correlation. This is demonstrated by the bar chart (Figure 1). Other studies have demonstrated a seasonal increase in the rate of non-traumatic aortic dissections in the winter $[5,6]$. The same seasonal variation has been noted in several studies for ruptured abdominal aortic aneurysms (AAA) with an increase in incidence in the winter $[7,11,12]$. One study found a statistically significant correlation with rupture of AAA and mean atmospheric pressure [8] and the only other published studies found no correlation between the incidence of ruptured AAA and barometric pressure or humidity $[7,13]$. There have also been studies examining the incidence of other vascular disruptions with changing season and weather conditions. In one study a modest correlation was found between high atmospheric pressure, daily change in pressure and the risk of rupture of subarachnoid aneurysms [9]. Another study demonstrated seasonal variation in spontaneous cervical artery dissection [10].

Previous work has shown that the only physiological parameter positively associated with atmospheric pressure is arterial blood gas concentrations [14]. However the exact mechanism by which reduced arterial oxygen tension may cause rupture of an aneurysm of dissection remains unknown. The onset of labour is the only other medical change thought to be associated with falling atmospheric pressure [15]. Though this possible association may not seem immediately useful, it is known that pregnant women have a higher incidence of spontaneous aortic dissection [16].
The analysis in our study involved using accurate meteorological data and operation dates from a regional cardiothoracic centre covering a large geographical area. Despite careful methodology there are potential errors that must be remembered. The weather station, although centrally placed over the catchment area, may not have reflected the patients' movements over the region in that time period and does not account for weather variations over an area 50 miles in diameter.

There is also likely to be variability in the timing of presentation. Some patients may have begun aortic dissection a long time prior to presenting to hospital and a tamponading effect may have slowed the progression of collapse. We have attempted to account for this by looking at weather data in both the 24 and 48 hour time periods prior to the day of operation. It may be that a sudden change in the indicator being examined between 48 and 24 hours prior to dissection may be related to the onset of dissection.

Only patients who had surgery were included in this study and there are undoubtedly others who either did not survive long enough to have surgery or who were managed without surgery. It is presumed that the inclusion of these patients would not have changed the trends obtained in relation to weather conditions. In practice this study may not have any immediate applications to alter clinical practice, but serves to further elucidate the complex aetiology of a rare and sometimes lethal condition.

\section{Conclusion}

This study is the first to examine the relationship between atmospheric pressure, temperature and dissecting thoracic aorta, and was unable to demonstrate any statistically significant relationship.

\section{Competing interests}

The author(s) declare that they have no competing interests.

\section{Authors' contributions}

$\mathrm{CR}$ and NC drafted the manuscript. CR conceived the study. Statistical analysis was performed by ED of the statistics department (see acknowledgements). CR and NC participated in its design and coordination. All authors read and approved the final manuscript.

\section{Acknowledgements}

We would like to thank the Blackpool Victoria Hospital Cardiothoracic Unit for the use of their hospital data, the Meteorological Office for the use of their temperature and atmospheric pressure data, and Emma Dark of North Bristol Healthcare Trust, for her help with statistical analysis. 


\section{References}

I. Shennan T: Dissecting aneurysms. Medical Research Council (Great Britain). In Special report series. No 193 London: His Majesty's Stationery Office I3f; 1934.

2. Lansmann SL, Raissi S, Ergin MA, Griepp RB: Urgent operation for acute transverse aortic arch dissection. J Thorac Cardiovasc Surg I989, 97:334-4I.

3. Goodwin J, Pearce VR, Taylor RS, Read KLQ, Powers SJ: Seasonal cold and circadian changes in blood pressure and physical activity in young and elderly people. Age and Ageing 200I, 30:31 $1-317$.

4. Minami J, Kawano Y, Ishimitsu T, Yoshimi H, Takishita S: Seasonal variations in office, home, and $24 \mathrm{~h}$ ambulatory blood pressure in patients with essential hypertension. J Hyperten 1996, | 4: |42|-|425.

5. Manfredini R, Portaluppi F, Salmi R, Zamboni P, La Cecilia O, Kuwornu Afi H, Regoli F, Bigoni M, Gallerani M: Seasonal variation in the occurrence of non-traumatic rupture of thoracic aorta. Am J Emerg Med 1999, I 7(7):672-4.

6. Upshur RE, Mamdani MM, Knight K: Are there seasonal patterns to ruptured aortic aneurysms and dissections of the aorta? Eur J Vasc Endovasc Surg 2000, 20(2): I73-6.

7. Sterpetti AV, Cavallari N, Allegrucci P, Agosta F, Cavallaro A: Seasonal variation in the incidence of ruptured abdominal aortic aneurysm. J R Coll Surg Edinb 1995, 40(I): |4-5.

8. Bown MJ, McCarthy MJ, Bell PR, Sayers RD: Low atmospheric pressure is associated with rupture of abdominal aortic aneurysms. Eur J Vasc Endovasc Surg 2003, 25(I):68-7I.

9. Buxton N, Liu C, Dasic D, Moody P, Hope DT: Relationship of aneurysmal subarachnoid haemorrhage to changes in atmospheric pressure: results of a prospective study. J Neurosurg 2001, 95:391-392.

10. Schievink WI, Wijdicks EF, Kuiper JD: Seasonal pattern of spontaneous cervical artery dissection. I Neurosurg 1998, 89(I): $101-3$.

II. Ballaro A, Cortina-Borja M, Collin J: A seasonal variation in the incidence of ruptured abdominal aortic aneurysms. Eur J Vasc Endovasc Surg 1998, I 5(5):429-31.

12. Varty K, Reid A, Jagger C, Bell PR: Vascular emergencies: what's in season? Cardiovasc Surg 1995, 3(4):409-II.

13. Kurtoglu M, Yanar H, Aksoy M, et al.: Seasonality in the incidence of abdominal aortic aneurysm ruptures: a review of eight years. Ulus Travma Derg 2004, I O(I):39-4I.

14. Burnett RW, Itano M: An interlaboratory study of blood-gas analysis: dependence of $\mathrm{pO}_{2}$ and $\mathrm{pCO}_{2}$ results on atmospheric pressure. Clin Chem 1989, 35: I779-I798I.

15. Noller KL, Resseguie LJ, Voss V: The effect of changes in atmospheric pressure on the occurrence of the spontaneous onset of labour in term pregnancies. Am J Obstet Gynecol 1996, I 74: I 192-II97.

16. Williams GM, Gott VL, Brawley RK, Schauble JF, Labs JD: Aortic disease associated with pregnancy. J Vasc Surg 1988, 8(4):470-5.

\section{Pre-publication history}

The pre-publication history for this paper can be accessed here:

http://www.biomedcentral.com/1471-2482/5/21/prepub 